\title{
Effect of Communication Intervention Strategies on Awareness, Knowledge and Perception of Teachers' on Substance Abuse Among Adolescents in Yaba/Shomolu Local Government
}

\author{
Mofoluke Akoja, $\mathrm{PhD*}$ \\ Veronica Adeleke School of Social Sciences, Mass Communication Department, \\ Babcock University, Ilisan-Remo, Ogun State \\ Titilayo Adefarasin \\ Mass Communication Department, Babcock University, Ilisan-Remo, Ogun State
}

\begin{abstract}
The use of non-conventional drug is one of the risky behaviours adolescents practice due to lack of knowledge on the negative implications. This however raises serious concerns on the well-being and quality of life of adolescents who have devised new methods of abuse apart from the conventional methods and drugs. The school appears to be the place where this is practiced and transferred. The study assumes that this problem may persist and leave grave consequences if teachers especially are unaware of this fact. To curtail this, the study examined the effectiveness of communication intervention strategies such as the use of seminars, posters and fliers to improve the level of awareness, knowledge and perception of teachers on substance abuse among adolescents in selected secondary schools in Yaba/Shomolu, Lagos state. Premised on the elaboration likelihood model theory of persuasion and change of attitude as well as the source credibility theory, true-experimental design was used to collect data from 62 teachers $(35=$ experimental and $27=$ control $)$ from the four schools selected purposively at both pre and post-intervention stages. Findings revealed a significant difference in the level of awareness (premean=71.48; post-mean=92.54), knowledge (pre-mean=51.14;post-mean=59.4) and perception (premean=23.48;post-mean=27.02) of experimental groups on substance abuse among adolescents while that of the control groups remained the same. The study concludes that communication intervention strategies have positive effects on teachers' level of awareness, knowledge and perception of substance abuse among adolescents. Recommendations were centred on the need for teachers to adopt preventive strategies in tackling this negative health practice among adolescents.
\end{abstract}

Keywords: Substance abuse, Awareness, Knowledge, Perception, Communication Interventions.

DOI: $10.7176 / \mathrm{NMMC} / 83-05$

Publication date:September $30^{\text {th }} 2019$

\section{Introduction}

Okoye (2001) cited in Fareo (2012), defines a drug as a substance that causes different biological changes in through its che【30】 mical actions. Further, Ojo (2018) noted that drugs are chemical substances used to confer health benefits to the user in measured amounts. From ancient times, drugs, either in liquid or solid substances, perform functions such as healing and prevention of diseases. Therefore, a drug is a liquid or solid substance aimed at treating an illness or preventing a disease in the body of a person or an animal. Impliedly, drugs change the way the brain and body functions. It can cure or prevent diseases if used correctly and if used incorrectly could result in negative changes in the body system leading to a condition popularly described as substance abuse. Substance abuse is the excessive and wrong use of psychoactive drugs which alter brain functions causing negative changes in the human body. Clearly, it is the incorrect use of substances such as alcohol, illegal drugs, prescribed drugs without authorized consent, for purposes such as pleasure, being fit for better performance in certain situations or changing perception of reality that eventually leads to negative changes in the body. There is abuse when these substances are used in ways that do not meet the prescribed requirement. The danger here is that drugs tend to change an individual's physiological behaviour pattern when in the body and can, if prolonged, result in physical, psychological and physiological damage. One of the behavioural problems associated with abuse of substances is addiction.

The practice of substance abuse among adolescents is a major lifestyle problem in every part of the world including Nigeria (Ojo, 2018; Okpala, 2015; Mamman, Othman \& Hooi Lian, 2014; United Nations Office of Drugs and Crime; UNODC, 2005 cited by Fareo, 2012) The National Drug Law Enforcement Agency affirmed the fact that adolescent substance abuse is not just a disturbing health-related phenomena in Nigeria, it is now of global concern (Fareo 2012 cited in NDLEA, 1997). This is because many of these young ones perceive a drug user as one who is strong, tough and bold. Fareo (2012) further noted that students who use drugs are those who feel inadequate and as such are in search of social acceptance. Some substances that are commonly abused by youths in Nigeria are: Marijuana, commonly referred to as 'weed or ganja' by youths. It contains 
tetrahydrocannabinol (THC), which when consumed excessively, leads to various psychological and physiological effects on the body such as anxiety, high blood pressure, panic attacks and difficulty in memory and learning. Another one is Cocaine, also referred to as 'coke or crack' among youths. The excessive use of cocaine leads to restlessness, anxiety, panic and paranoia. Heroin, commonly referred to as 'dope or hero' is equally common among youths. The constant use of this drug leads to depression, difficulty in urination, nausea, vomiting, unconsciousness and death. Lastly, Alcohol, which is commonly referred to as 'juice or booze' among youths.

Scholars (Obiechina \& Isiguzo, 2016; Anyanwu, Ibekwe \& Ojinnaka, 2016) have attested to the fact that substance abuse is becoming a problem largely because of the high cost of purchase of conventional drugs, as well as the law penalties associated with them. Adolescents have innovated new methods of substance abuse to make them feel high, excited or gain pleasure by using licit drugs such as over-the-counter drugs including codeine found in cough syrups, tramadol, rophynol, as well as inhalants from burning plastics, methylated spirit, amongst others. The National Institute on Drug Abuse (2014) compared an adolescent's brain to a car with a fully functioning gas pedal but weak brakes (prefrontal cortex). In other words, the effects of these substances on students can lead to developmental impairment as well as expose the individual to the risk of becoming a drug addict and social nuisance. Over the years, communication has been attested to as effective in increasing awareness, knowledge and altering attitudes. Based on this fact, it is believed that when deployed strategically, people can be more effectively educated and convinced. Carey (2008) acknowledged that communication is instrumental in the acquisition of knowledge. In this vein, communication intervention messages are aimed at changing behaviour including harmful health practices. Communication interventions are effective in persuading individuals to act on behalf of their own health by doing the right things. Both policymakers and practitioners affirmed the effectiveness of these messages in reducing substance abuse even though there is a tendency for them to be counterproductive if not well coordinated (European Monitoring Center for Drugs and Drug Addiction, 2013). Communication intervention messages have helped improve actions of people suffering from health problems such as autism, as well as an individual's overall well-being (Paul; 2008, Ortega and Barriuso, 2013; Lofland, 2014). The potential of communication messages lies in its tendency to spread simple and fixed messages to a specific audience for a period of time until a change occurs (European Drug and Drug Addiction Monitoring Centre, 2013). It is also assumed that a large and heterogeneous proportion of a population can be reached with communication messages (Wakefield, Loken \& Hornik, 2010 by the European Monitoring Center for Drugs and Drug Addiction, 2013). Therefore, communication intervention messages were designed to create awareness and knowledge of teachers on the new methods of substance abuse among adolescents and the harmful effects of these substances. By conducting seminars and distributing flyers and posters, the study examined the level of awareness, knowledge and perception of teachers in four selected secondary schools in Yaba/Shomolu, Lagos state at the pre-intervention and post-intervention levels.

\section{Substance Abuse among adolescents}

For centuries, man has either made attempts to balance good aspects of life or avoid the bad by consuming various substances, be it licit or illicit. Studies have shown high prevalence of substance abuse locally and globally (Oshikoya \& Alli, 2006; Okpala, 2015; Obiechina \& Isiguzo, 2016; Sahu \& Sahu, 2012.). This is even more common among the adolescents who are at the stage which involves exploring of identity, independence, and thinking critically about self and the world around (National Social Workers ' Association, 2003). Logan (2014) concludes that adolescents experimenting with substances is not a new occurrence, or a problem that would immediately improve. For many reasons, adolescents use drugs to determine the effectiveness of a particular drug, get high, relieve stress, or feel grown up. It was found that 22.1 percent of Nigerians ages 12 to 17 use tobacco. Substance abuse with physical and mental health problems remain the major risk behaviour among adolescents (Mamman, Othman \& Lian, 2014). Despite the recognized risks associated with these substances, the practice persist. Substance abuse causes a lot of adolescent harm including gangsterism and cultism, armed robbery, mental illness, blood-bone illness, and death. Studies revealed that from a young age, most drug addicts started smoking. However, adolescents are inclined to look for new thrills as they grow older and gradually enter hard drugs. In a study cited by Mamman et al (2014), 65\% of high school students use drugs to have good time, $54 \%$ wanted to experiment to see what it was like, while $20-40 \%$ used it to change their moods.

According to Akannam (2008) cited in Mamman, et al (2014), the drug abuse record in Nigeria indicates that the North-West has a prevalence rate of 37.47 per cent, South-West (17.32\%), South-East (13.5\%), NorthCentral (11.71\%), while North-East has (8.54\%). The United Nations Office on Drugs and Crime (2007) in Mamman, et al (2014) points out that in Nigeria, substance abuse is common among males at 94.2 per cent; while females stands at 5.8 per cent with the age of first use being 10 to 29 years. Males are more involved in substance abuse than females even in the school environment and adolescents over the age of 10 are known to be involved in drug experiments. In this study, substance abuse is the wrong, excessive and harmful use of legal 
prescription drugs as well as other easily accessible substances in form of inhalants, which the study describes as 'alternative drugs', such as inhaling smoke from burning plastics, rubber tyres, gas lighters, cellophane, methylated spirit, amongst others by adolescents. It has been found that adolescents use these alternatives because they cannot afford the conventional ones such as marijuana, cocaine, alcohol and heroin. Meanwhile, the problem of substance abuse knows no limits or social class as it obstructs the development of any society; being a threat to life, well-being, poise and affluence of all individuals (Okpala, 2015). Substance abuse respects no one and if not properly managed can lead to addiction, which can result to serious problems for an individual and the society as well (Vanguard, 2013).

A 2013 study revealed that about $22.1 \%$ of students in private schools and $15.3 \%$ of students in public schools use psychoactive substances bringing the total to $37.4 \%$ of students who use drugs (P.M. News, 2017). The factors influencing student substance abuse include peer pressure, curiosity, ignorance, academic frustration, and lack of parental care (Vanguard, 2016). There is no doubt that the adolescent age is characterized by new personalities, peer selection, adventurism, curiosity, pleasure and confusion of role. These may be fuelled by lack of home or school guidance which may lead to the choice of friends who will encourage non-conventional drug experimentation.

Young people usually refer to inhalants as a huff. Other inhalant names include: Glue, gas, petrol, sniff, chroming and poppers. Alcohol and Drug Foundation (2018) defines inhalants as common vapour-producing household, industrial and medical products in which some people inhale (breathe in) to make them feel poisonous or high. Inhalants are products that are easily accessible and available such as: vegetable oil, spray, nail polish, gasoline, spray paint, markers, electronic contact cleaner, spray (deodorant, hairspray, computer duster spray), shoe polish, chrome-based paint, felt-tipped pens, correction fluid, gas lighters, cleaning fluids, glue, petrol, nitrous oxide, among others. Usually inhalants are breathed into the nose or mouth. Before being inhaled, they may be sprayed into a plastic bag, poured into a bottle or soaked in a cloth or sleeve. They are sometimes inhaled directly from the container or sprayed into the mouth or nose (Alcohol and Drug Foundation, 2018). This method is perceived to be very dangerous because it can cause suffocation although while the side effects may include intoxication, nausea, headaches, injuries, seizures, pneumonia, dependence, brain damage, coma, abnormal heart rhythm, irritability and depression, loss of memory, reduced attention span and ability to think clearly, pimples around the mouth and lips, pale appearance, tremors, weight loss, fatigue, excessive thirst, loss of sense of smell and hearing, witness problems, among others. Inhalant drugs may seem safer, than conventional drugs such as heroin, cocaine, but they are just as dangerous as not only can inhalant abuse lead to addiction, it can also lead to serious long-term health effects and sometimes even death (Next Generation Village, 2018).

\subsection{Creating awareness and knowledge on substance abuse using communication}

Simply defined, communication is the exchange of meaningful information through a medium for the purpose of getting feedback. Normally, communication should occur in two ways between a sender and a receiver playing interchangeable roles. Communication is not complete without a feedback from the receiver of the message. Rimal \& Lapinski (2009) underscored the importance of communication by describing it as the core of who we are as human beings usually involving the exchange of information signifying our symbolic capability. For communication to be effective, different strategies may be deployed to improve its influence on behavior. These information (messages) can be packaged in books, photographs, songs, movies, posters, flyers, seminars, among others, with the intent of creating awareness, informing or educating a specific audience in order to achieve behavioural change (Rimer \& Kreuter, 2006). Any attempt by intervention to change behaviours are acts of communication. In the formal sense, however, target audiences are perceived as members of social networks that interact, participate in social ceremonies, and derive from one another (Rimal \& Lapinski, 2009).

Communication intervention will be meaningful depending on the extent to which the recipients are involved in the issue the communication is addressing, considering it, finding it relevant and important and intending to act on it. Rimal and Lapinski (2009) stressed that communication interventions involves receiving information and processing it by individuals who determine not only what people encounter (through selective exposure processes), but also the meaning they derive from communication (known as selective perception), depending on factors in both individuals. Research shows that communication intervention messages have achieved modest success in changing a number of health-related issues such as cancer-related behaviours, smoking, diet, exercise, HIV/AIDs, among others (Rimer \& Kreuter, 2006; European Monitoring Center for Drugs and Drug Addiction, 2013; Okorie, 2013). Communication intervention messages has influenced many aspects of human life including shaping behavior in particular ways, shaping individual opinions and beliefs, or even providing information that can distort the knowledge of a particular topic. The communication field is a dynamic one, and the general public is now criticizing it more. Even at that, the overall influence of communication intervention strategies or messages has dramatically increased over the years and will continue to grow as technology improves. This is because messages sent simultaneously reach a large heterogeneous 
audience uniformly covering different issues, including health, music, human interest, art, crime, sport, and political events (Soola, 2009; Okorie, 2013). It can equally provide health ideas and new information on health issues to a specific audience with the aim of informing, educating, forming public opinion or discourse, creating awareness-raising, persuading and social mobilization. In other words, communication intervention can be a powerful means of penetrating every segment of society with meaningful health and principle messages. In addition, communication intervention messages can be packaged to create awareness and knowledge about issues of national interest.

Several studies have observed the power of communication messages in creating awareness and knowledge and to prevent adolescent substance abuse (Dejong \& Winsten, 2018; European Monitoring Center for Drugs and Drug Addiction, 2013; Hetcht \& Miller-Day, 2017). DeJong and Winsten (2018) explain that public health educators have used communication intervention strategies for the past twenty-five years as a means of preventing substance abuse. The effectiveness of interventions in helping people suffering from health problems such as autism has been demonstrated in some intervention studies (Paul, 2008; Ortega and Barriuso, 2013; Lofland, 2014). Communication intervention has proved effective in helping individuals with intellectual and developmental disabilities, according to Snell, Brady, McLean, Ogleetree, Siegel, Sylvester, Mollica, Paul, Romski and Sevcik (2011) at the rate of 95.7 per cent of the 116 studies reviewed. Harrington, Noble and Newman (2004), reveal that half of the interventions resulted in increased patient involvement.

\subsection{Forms of Communication Intervention Strategies for creating awareness and knowledge on Substance Abuse}

Given that, substance abuse is a major public health concern affecting students in secondary schools in Nigeria, using communication intervention strategies in creating the awareness and knowledge for teachers on substance abuse is explored. The following forms of communication intervention strategies suggested by experts were adopted in creating awareness and knowledge, as well as to facilitate a change in the perception of teachers on substance abuse among secondary school students.

\subsubsection{Use of Posters in creating awareness and knowledge:}

A poster is a popular communications medium whose job is simply to communicate information. Canada's National Arts Center (2018) defines a poster as a "public" piece of paper that transmits information via text (words) and/or graphic images (symbols or images). In other words, it is any piece of printed paper mounted on a flat or wall surface. Typically, posters include both textual and graphic elements, but they can either be entirely graphic or in text form. Posters are designed specifically to be attractive and informative. It is generally designed for vertical display on a wall or window usually large enough to be seen and read from a relatively short distance. The main target audience is the walking person or passers-by. With immediacy and purpose, a poster must convey its message because people on the street are often in a hurry (Canada's National Arts Centre, 2018). Samanez (1987), mentions that instead of other forms of communication, posters provide an alternative medium for communicating to the public. A poster must have visual attractiveness in order to create awareness and knowledge, and the message must be well presented with metaphors, symbols, gestures, and detailed description. Consequently, the message's appeal allows the audience to logically and emotionally accept the message. Samanez (1987) also explains that the message force targets memory bearing conviction and calls for action. The message therefore needs to be precisely defined for the target audience. Ilic \& Rowe (2013) affirmed that posters are commonly used to communicate information about academic and public health. Other well-designed studies also buttress the point that posters are effective in achieving knowledge transfer (Duchin \& Sherwood, 1990; Randolph \& Viswanath, 2004; Keely, 2004). Therefore, graphical and textual posters were designed and pasted on the walls of the selected secondary schools as a means of creating awareness and knowledge as well as positively influencing the perception of teachers on their roles in curbing substance abuse among students.

\subsubsection{Use of Flyers in creating awareness and knowledge}

Another means of communication is a flyer which is a brochure or leaflet providing adequate information about a problem. Nearly everyone can produce flyers. An individual who has a printer or someone who can draw well has the ability to produce flyers because they are easy to develop and a low-cost way of distributing information (Peters, 2018). Flyers are also referred to, among others, as leaflets, handbooks, brochures. Flyers are a great way to pack information into a simple, eye-catching design that attracts the public by providing basic information (Pennisi, Gunawan, Major \& Winder, 2011). This means that flyers should contain the information needed to capture a reader's attention. Flyers are important tools of communication in creating awareness and impacting knowledge. Peters (2018) explains that flyers are an effective tool for influencing public opinion as they can reach wide and specific audiences and are accessible to people otherwise isolated from illiteracy or poverty. Therefore, colourful flyers were designed for the purpose of this study, to create awareness and knowledge of substance abuse among students for teachers in selected schools. During the seminar, the flyers were distributed to reinforce the impact of the message and as a way of preserving the knowledge gained during the seminar which is the third strategy. 


\subsubsection{Use of Seminars in creating awareness and knowledge}

Vishal (2018) describes a seminar as a group of individuals who come together to discuss and learn specific techniques and topics. These meetings are usually interactive sessions in which participants engage in discussions on the defined topic. Often, one or two presenters lead the sessions that serve to guide the discussion along the desired path. In addition, seminars expose people to a wealth of knowledge that is usually presented at a specific time and place by many speakers (Vishal, 2018). Often this can be done through on-going dialogue with a seminar leader or instructor or through a more formal presentation of research. Seminars can be a viable means of educating teachers about substance abuse among students. In the sense that the seminar leader, who is skilled in substance abuse, will be able to thoroughly educate and inform teachers about the causes, signs, effects, and overall threat of substance abuse among students. The seminar conducted provided teachers with the opportunity to ask questions about substance abuse among students as well as clarify any doubts that may have. Nevertheless, the posters and flyers were handy materials providing additional information and a way of reminding participants of the knowledge gained. Thus, seminars were used for the purpose of this research to expose and educate teachers on the new methods of substance abuse among students to facilitate a change in teachers' post-intervention perception of the issue.

\subsubsection{The School as a prevention intervention for substance abuse among adolescents}

The school is an important factor in student substance abuse prevention. Several studies (Office of Drugs and Crime of the United Nations, 2004; American Academy of Paediatrics, 2007; Stigler, Neuel and Perry, 2011) all have observed and demonstrated this fact. Young (2011) defines school as distinctive institutions to enable pupils acquire knowledge that is not available at home or in their daily lives. Young (2011) argues that schools have a distinct role to play in modern societies in providing access to concepts that allow young people to move beyond their experience in ways that are not open to them in their families and communities. This implies that school's role in the life of a child goes beyond basic curriculum education. For most teenagers, this is why the school is called the physical, social, and psychological "home away from home." Arevian \& Khasholian (2014) certifies that schools are one of the best places to provide health education on primary substance abuse prevention. School-based prevention intervention is part of community-based prevention intervention aimed at reducing youth demand for harmful legal products (Johnson, Courser, Holder, Miller, Ogilvie, Moore, Collins, Saltz, Ogilvie \& Saylor, 2007). It is concerned with information about risks and local norms, as well as life skills, to resist social influences to consume or abuse harmful legal products. These abilities are taught using a combination of teaching techniques for behavioural purposes including demonstration, behavioural rehearsal, feedback and reinforcement, and homework assignments. Information is also provided to reinforce non-drug standards and reduce normative expectations for drugs (Botvin et al., 2001;Griffin et al., 2003 cited by Johnson, Courser, Holder, Miller, Ogilvie, Moore, Collins, Saltz, Ogilvie \& Saylor, 2007).

The school naturally plays a key role in substance abuse education, prevention and early identification (American Academy of Paediatrics, 2007). This is because the school is a teaching place; education and cultivation of good habits as well as proper structuring or moulding of future leaders. Schools should therefore focus on reducing drug demand, reducing drug supply and mitigating the health and social consequences of drug abuse (United Nations Office of Drugs and Crime, 2004). The school has to strategize prevention interventions or programs to curb the threat to address the problem of substance abuse among students. However, the school should not accept sole responsibility for changing the behaviours of student health, including reducing drug abuse. Schools should be willing to use evidence-based programs to identify substance abuse students and refer to the hospital. Combating substance abuse among high school students in Nigeria, however, will require serious collective efforts. Most schools have been found to have some policies in place against substance abuse among students (Obiechina and Isiguzo, 2016; Okpala, 2015; Afolabi, Ayilara, Akinyemi \& Ola-Olorun (2012)). However, most of these policies are severe such as suspension and, in the worst case scenario, expulsion from school for students testing positive for abuse substances. But that's paradoxical. In the sense that, these schools perceive that the appropriate assistance they can give to students suffering from substance abuse is suspension or expulsion to prevent other students from becoming involved in drugs, exposing the former unknowingly to the doom of freedom to become problematic drug addicts and harm to society. Rather, schools should look for preventive measures to help substance abuse students. As a result, Nigerian high school teachers are indifferent to students who abuse substances as well as unaware of the emerging trend of substance abuse among students. Thus, for the purpose of this research, communication intervention tools in form of seminars, flyers and posters were employed to create awareness and provide foundational knowledge as well as change the perception of teachers on substance abuse among students in selected secondary schools in Yaba/Shomolu local government, Lagos.

\subsection{Review of Related Empirical Studies}

A study by Ronoh (2014) on the effectiveness of drug and substance abuse prevention programs in selected public and private universities in Kenya among counsellors, chaplains, wardens, security officers and working 
housekeepers with students and social support providers. Using questionnaire, Focus Group Discussions guide and qualitative interview schedule as data collection instruments, the study revealed the effectiveness of prevention programs in unveiling workable strategies that could be applied to prevent substance abuse by university stakeholders and their adverse impact.

Bradley (2009) investigated the effects of a school-based motivational intervention on adolescent substance abuse. The study investigated the effects of motivational interviewing on smoking in a small school-based adolescent population and tested the hypotheses that motivational interviewing would result in a reduction in substance use compared to evaluation only and an increase in the readiness of each participant to change. The study used randomized controlled design to determine the effectiveness of the adolescent substance abuse motivational intervention, of which participants only had to select a motivational intervention or evaluation between two 30-minute sessions. Before and one month after the intervention, evaluations were administered. The results showed that the intervention was effective in reducing the daily use of cigarettes and cigarette dependence symptoms for experimental group participants. The results showed that the intervention could be implemented as a standard therapy to use motivational interventions in school setting to decrease the use of adolescent substances.

Another study by Kalantarkousheh, Rasouli, Abolfathi \& Nouri (2014) examined the effectiveness of teaching communication skills to decrease the trend of addiction in male students of Guidance School using the control group design pre-test/post-test that included all guide school male students studying in Tehran Province cities. Using random sample cluster method, a total of 30 male students were selected. Half of the population was classified as the test group and the rest was the control group. The test group had weekly educational interventions of eighty to 90 minutes. The study results revealed that there was a significant difference between the test and control groups in the number of addiction tendencies. It showed that communication skills promoted control of health and addiction and decreased drug use by increasing the ability to solve problems and decreasing interpersonal conflicts. The results of this research also support the results of previous studies on teaching communication skills effectiveness in the prevention of drug abuse.

Mahmood, Othman, Al-Tawli \& Al-Hadithi (2018) examined the effect of educational intervention on high school students to improve their knowledge and consequences of substance abuse in order to motivate them to take protective measures against substance use. The quasi-experimental design (one group; pre-and post-test) was used in this study and was performed from January 2017 to June 2017 in Erbil City. A random sampling technique was used to gather a sample of 280 students from four high schools in Erbil City, the capital of the Kurdi-stan Region-Iraq. Based on extensive review of literature and expert opinion, a structured teaching program was developed for the group to impart knowledge on various aspects of substance use. The program of intervention consisted of a series of four modules of education. Mainly "Rabers" taught these modules over a four-week period (one session per week). The study results revealed a pre-and post-intervention survey of a total of 270 students out of 280 students. The study concluded that implementation of a substance use education program on high school students in Erbil City had enhanced students ' knowledge of substance use.

\subsection{Theoretical Framework}

This study is premised on two theories - the Elaboration Likelihood Model and Source Credibility.

\section{Elaboration Likelihood Model Theory}

The elaboration likelihood model theory of persuasion and change of attitude was propounded by Richard E. Petty and John Cacioppo in 1980. Petty and Cacioppo (1986) aimed at providing a general framework for the organization, classification and understanding of the basic processes underlying the effectiveness of persuasive communication. Kendra (2018) asserts that the Elaboration Likelihood theory proposes two ways in which people's attitude can be altered. First, people can be motivated to listen and think about a message, thus leading to an attitude shift while the second affirms that people might be influenced by features or characteristics of the speaker, leading to a temporary shift in attitude. Furthermore, the theory assumes that messages that are thoughtprovoking or targeted at emotions as well as appeal to logic are considered to lead to permanent changes in people's attitude and creates a new dimension of perception. For this study, the assumption of the theory stating that people are motivated to listen and think about a message thereby leading to a change in attitude is relevant. In relation to the study, the messages from the seminars on substance abuse among students were comprehensive and effective in increasing or creating awareness and knowledge for teachers as well as alter their perception or a change in attitude on how to prevent substance abuse among students. This was achieved by emphasizing prevention and suggesting measures rather than severe punishment such as suspension or expulsion. The presentations, included videos, images and stories portraying real life shown during the seminar on cases of students who abused substances and suffer addiction which further led to physical and psychological problems or in worst cases, death. Such messages impressed the teachers desire to be willing to take preventive measures to avoid such instances from befalling their students.

Source Credibility Theory 
The source credibility theory simply deals with the credibility and expertness of a source of message for people to accept it as trustworthy. Hovland Carl, Janis Irving and Kelley Harold propounded it in 1953. This theory states that when a source presents itself as credible, people are more likely to be persuaded (Umeogu, 2012). This implies that people will only accept a message based on how they perceive the credibility of that source. Source credibility theory also assumes that the credible sources of communication regardless of format, can heavily influence the attitude of people. Hovland and Weiss (1951) conducted a study on the influence of persuasive sources, and this was done by comparing credible and non-credible sources using the same persuasive message to test if the sources considered credible could influence the audience's change of attitude more than the non-credible source. The study confirmed that credible sources tend to have a desired impact on the audience. The fact that the resource person who handled the seminar presented to the experimental group is a communication expert who demonstrated depth of knowledge on the subject contributed to the acceptance and believability of the information shared.

\section{Method of the Study}

The study employed the true-experimental research design using the survey research method to collect quantitative data. The population of the study was the total aggregate of teachers in Yaba/Shomolu local government (504 teachers). Yaba/Shomolu was purposively selected as the location of the study because of the high availability of drugs and the rate of drug addiction cases reported particularly at the Federal Neuro Psychiatric Hospital, famously known as 'Yaba Left' (Punch, 2016; Punch, 2017). Four secondary (private and public) schools in Yaba/Shomolu were selected randomly from a list of both private and public secondary schools. Using the total enumeration sampling technique, all teachers in the four selected schools were sampled given the fact that the size was manageable $(35,38,22,30)$. A structured questionnaire served as the instrument of data gathering. Participants were divided into two groups - the experimental and control groups. Both experimental and control groups consisted of two schools each (a public and a private school in Yaba/Shomolu). While teachers in Angus Memorial High School and Topgrade secondary school made up the experimental group, the control group consisted of teachers in Shomolu High School and Thonix Immaculate High School. Both experimental and control groups filled the questionnaire at first to test their level of awareness and knowledge as well as their perception of substance abuse among adolescents (pre-test). Thereafter, the communication interventions (seminars, flyers and posters) were administered solely to the experimental groups and were given a period of one month each to determine the effect of the interventions on their level of awareness, knowledge and perception of substance abuse among adolescents (post-test). However, the control groups were not exposed to the communication interventions through seminars, flyers or posters. After the one month of observation, copies of the same questionnaire were re-administered to both groups to determine the effectiveness of the intervention on the teachers (experimental) and to discover other means through which awareness, knowledge and perception of teachers were impacted based on the result of the control groups. With a return rate of 62 out of the 125 copies administered, between both groups at pre-and post-intervention stages, data was analysed using descriptive statistical tools while the hypotheses were tested with the Paired T-test to determine the level of significance in terms of the differences observed at pre-intervention and post-intervention stages. 


\section{Findings and discussion}

4.1: Teachers' level of awareness on substance abuse among students in selected secondary schools in Lagos pre and post intervention

Table 4.1: Pre-intervention level of awareness of teachers on substance abuse among students

\begin{tabular}{|c|c|c|c|c|}
\hline \multirow[b]{2}{*}{ Statements on Awareness of Substance abuse among students } & \multicolumn{2}{|c|}{ Control } & \multicolumn{2}{|c|}{ Experimental } \\
\hline & $\begin{array}{l}\text { Mean } \\
(\overline{\mathbf{X}})\end{array}$ & SD & $\begin{array}{l}\text { Mean } \\
(\overline{\mathbf{X}})\end{array}$ & SD \\
\hline $\begin{array}{l}\text { I am aware that students have innovated new methods of substance abuse } \\
\text { as alternatives apart from the conventional drugs. }\end{array}$ & 3.63 & 1.275 & 3.97 & .707 \\
\hline I am aware that both male and female students abuse drugs & 4.19 & 1.001 & 4.37 & 690 \\
\hline $\begin{array}{l}\text { I am aware that substance abuse can lead } \\
\text { to developmental problems in students }\end{array}$ & 4.33 & 1.000 & 4.57 & .558 \\
\hline $\begin{array}{l}\text { I am aware that students abuse over-the-counter drugs and inhalants } \\
\text { more than marijuana, cocaine, heroin etc. }\end{array}$ & 3.74 & 1.163 & 4.17 & .747 \\
\hline I am aware that students from ages 10-16 engage in substance abuse & 3.56 & 1.251 & 3.66 & 1.162 \\
\hline I am aware that students get substances from peers. & 4.07 & 1.107 & 4.23 & .877 \\
\hline $\begin{array}{l}\text { I am aware that students use pocket money, school fees, book fees to } \\
\text { buy substances }\end{array}$ & 3.74 & 1.196 & 3.89 & 1.051 \\
\hline \multicolumn{5}{|l|}{ I am aware that students abuse the following substances : } \\
\hline Methylated spirit & 3.52 & 1.369 & 3.40 & 1.418 \\
\hline Tramadol & 4.04 & 1.285 & 4.23 & 1.060 \\
\hline Rophynol & 3.67 & 1.301 & 3.51 & 1.380 \\
\hline Codeine & 4.00 & 1.301 & 4.00 & 1.328 \\
\hline Tyres & 3.00 & 1.330 & 2.97 & 1.599 \\
\hline Inhalants (markers, biro ink, nail Polish) & 2.93 & 1.466 & 3.17 & 1.361 \\
\hline Plastic bottles and plates & 2.89 & 1.219 & 2.83 & 1.445 \\
\hline Petrol & 3.19 & 1.415 & 2.94 & 1.533 \\
\hline \multicolumn{5}{|l|}{$\begin{array}{l}\text { I am aware that these are the signs } \\
\text { or symptoms of substance abuse in students: }\end{array}$} \\
\hline Mood swings & 3.78 & 1.368 & 3.94 & 1.056 \\
\hline Missing of school activities & 3.85 & 1.134 & 3.86 & 1.033 \\
\hline Red eyes & 3.96 & 1.192 & 3.97 & .954 \\
\hline Constantly asking for money & 3.85 & 1.064 & 3.80 & 1.079 \\
\hline Grand Mean & 3.86 & & 3.76 & \\
\hline
\end{tabular}

Decision rule: If mean $(\overline{\mathbf{X}}) \leq \mathbf{1 . 0 0}=$ Very low level; $1.1-2.0=$ low level; 2.1-3.0=Average; 3.1-4.0=high level; 4.1-5.0=very high level. 
Table 4.2: Post-intervention level of awareness of teachers on substance abuse among students

\begin{tabular}{|c|c|c|c|c|}
\hline \multirow{2}{*}{ Statements on Awareness of Substance abuse among students } & \multicolumn{2}{|c|}{$\begin{array}{l}\text { Control } \\
\text { group }\end{array}$} & \multicolumn{2}{|c|}{$\begin{array}{l}\text { Experimental } \\
\text { group }\end{array}$} \\
\hline & Mean & SD & Mean & SD \\
\hline $\begin{array}{l}\text { I am aware that students have innovated new methods of substance abuse } \\
\text { as alternatives apart from the conventional drugs. }\end{array}$ & 4.19 & 1.039 & 4.89 & .323 \\
\hline I am aware that both male and female students abuse drugs & 4.44 & .641 & 4.91 & .284 \\
\hline $\begin{array}{l}\text { I am aware that substance abuse can lead to developmental problems in } \\
\text { students }\end{array}$ & 4.52 & .849 & 4.91 & .284 \\
\hline $\begin{array}{l}\text { I am aware that students abuse over-the-counter drugs and inhalants more } \\
\text { than marijuana, cocaine, heroin etc. }\end{array}$ & 4.22 & .892 & 4.66 & .639 \\
\hline I am aware that students from ages 10-16 engage in substance abuse & 4.07 & .730 & 4.86 & .430 \\
\hline I am aware that students get substances from peers. & 4.19 & .962 & 4.89 & .404 \\
\hline $\begin{array}{l}\text { I am aware that students use pocket money, school fees, book fees to buy } \\
\text { substances }\end{array}$ & 4.30 & .775 & 4.91 & .373 \\
\hline \multicolumn{5}{|l|}{ I am aware that students abuse the following substances : } \\
\hline Methylated spirit & 3.52 & 1.528 & 4.83 & .568 \\
\hline Tramadol & 4.67 & .555 & 4.91 & .284 \\
\hline Rophynol & 3.81 & 1.415 & 4.94 & .236 \\
\hline Codeine & 4.67 & .555 & 4.91 & .284 \\
\hline Tyres & 2.96 & 1.506 & 4.77 & .646 \\
\hline Inhalants (markers, biro ink, nail Polish) & 3.00 & 1.519 & 4.71 & .710 \\
\hline Plastic bottles and plates & 2.37 & 1.445 & 4.80 & .632 \\
\hline Petrol & 3.41 & 1.575 & 4.83 & .382 \\
\hline \multicolumn{5}{|l|}{$\begin{array}{l}\text { I am aware that these are the signs or symptoms of substance abuse in } \\
\text { students: }\end{array}$} \\
\hline Mood swings & 4.26 & 1.023 & 4.97 & .169 \\
\hline Missing of school activities & 4.07 & 1.107 & 4.91 & .284 \\
\hline Red eyes & 4.22 & 1.086 & 4.97 & .169 \\
\hline Constantly asking for money & 3.93 & 1.141 & 4.94 & .236 \\
\hline Grand Mean & 3.94 & 1.070 & 4.87 & .386 \\
\hline
\end{tabular}

Decision rule: If mean $(\overline{\mathbf{X}}) \leq \mathbf{1 . 0 0}=$ Very low level; $1.1-2.0=$ low level; $2.1-3.0=$ Average; 3.1-4.0=high level; 4.1-5.0=very high level.

At the pre-intervention stage, both experimental $(\bar{X}=3.76)$ and control groups $(\bar{X}=3.86)$ had a high level of awareness of substance abuse among adolescents. This means that both groups were already aware of the new methods of substance abuse among adolescents even though this can still be improved. In a related health-based study, Bayamma (2015) affirms that at the pre-test, few people were aware of cervical cancer in the study prompting the need for an intervention to improve awareness on the issue, confirming the essence of the preintervention test conducted at the beginning of this study. At the post-intervention, the study revealed that the experimental groups level of awareness $(\overline{\mathrm{x}}=4.87)$ was very high while that of the control groups $(\overline{\mathrm{x}}=3.94)$ was high as well. This revealed that both groups respectively have a very high level of awareness that students have innovated new methods of substance abuse as alternatives apart from the conventional drugs $(\bar{x}=4.19, \bar{x}=4.89)$. This finding also shows that there is an increased level of awareness after intervention on both groups. Ishaak, Karel de Vries \& Van de Wolf (2014) however, disagrees with this finding, as the study asserts that at the posttest, only the experimental group obtained an increased awareness/knowledge of drugs, excluding the control group. Whereas, Bayamma (2015) supports this finding on the part of the experimental group, as the study states that among 60 samples selected, 5(8.4\%) had good knowledge of cervical cancer while $55(91.6 \%)$ had excellent knowledge of cervical cancer. Hence, the intervention in form of structured teaching programme enhanced the respondents' level of awareness on cervical cancer. 
4.2 Knowledge of teachers on substance abuse among students in selected secondary schools in Lagos pre and post intervention

Table 4.3: Pre-intervention knowledge of teachers on substance abuse among students

\begin{tabular}{|c|c|c|c|c|}
\hline & Contro & & Experi & mental \\
\hline Statements on Knowledge of Substance Abuse & Mean & SD & Mean & SD \\
\hline $\begin{array}{l}\text { I know that substance abuse is a pattern of harmful repeated use of drug or } \\
\text { alcohol use that often interferes with health, work or social relationships }\end{array}$ & 4.07 & 1.035 & 4.49 & .853 \\
\hline I know that substance abuse is usually for mood altering purposes & 3.89 & 1.121 & 4.14 & .912 \\
\hline I know the Factors that predisposes students to substance abuse : & & & & \\
\hline Peer pressure & 4.41 & .931 & 4.40 & .881 \\
\hline Psychological problems & 4.26 & .944 & 4.14 & .944 \\
\hline Family social status & 4.15 & .989 & 4.09 & .853 \\
\hline Extra income & 3.63 & 1.079 & 4.00 & 1.029 \\
\hline Accessibility & 3.93 & 1.141 & 4.26 & .919 \\
\hline I know that the harmful effects of drug abuse are: & & & & \\
\hline Health issues such as Mental illness & 4.56 & .974 & 4.63 & .646 \\
\hline Withdrawal & 4.19 & 1.039 & 4.34 & .802 \\
\hline Failure to meet up with assignments when due & 3.93 & .958 & 4.11 & .832 \\
\hline Social issues & 4.15 & .864 & 4.09 & 1.040 \\
\hline I know that substance abuse can be prevented and treated & 4.41 & .888 & 4.46 & .701 \\
\hline Grand mean & 4.13 & .996 & 4.26 & .867 \\
\hline
\end{tabular}

Decision rule: If mean $(\overline{\mathbf{X}}) \leq 1.00=$ Very low level; $1.1-2.0=$ low level; 2.1-3.0=Average; 3.1-4.0=high level; 4.1-5.0=very high level.

Table 4.4: Post-intervention knowledge of teachers on substance abuse among students

\begin{tabular}{|c|c|c|c|c|}
\hline \multirow[b]{2}{*}{ Statements on Knowledge of Substance Abuse } & \multicolumn{2}{|c|}{$\begin{array}{l}\text { Control } \\
\text { group }\end{array}$} & \multicolumn{2}{|c|}{$\begin{array}{l}\text { Experimental } \\
\text { group }\end{array}$} \\
\hline & Mean & SD & Mean & SD \\
\hline $\begin{array}{l}\text { I know that substance abuse is a pattern of harmful repeated use of drug or } \\
\text { alcohol use that often interferes with health, work or social relationships }\end{array}$ & 4.41 & .747 & 4.94 & .236 \\
\hline I know that substance abuse is usually for mood altering purposes & 4.37 & .688 & 4.91 & .284 \\
\hline \multicolumn{5}{|l|}{ I know the factors that predispose students to substance abuse : } \\
\hline Peer pressure & 4.78 & .506 & 5.00 & .000 \\
\hline Psychological problems & 4.37 & .967 & 4.94 & .236 \\
\hline Family social status & 4.30 & .724 & 4.94 & .338 \\
\hline Extra income & 4.15 & .818 & 4.89 & .323 \\
\hline Accessibility & 4.70 & .542 & 4.97 & .169 \\
\hline \multicolumn{5}{|l|}{ I know that the harmful effects of drug abuse are: } \\
\hline Health issues such as Mental illness & 4.78 & .506 & 5.00 & .000 \\
\hline Withdrawal & 4.63 & .492 & 4.94 & .236 \\
\hline Failure to meet up with assignments when due & 4.37 & .742 & 4.91 & .284 \\
\hline Social issues & 4.33 & .832 & 5.00 & .000 \\
\hline I know that substance abuse can be prevented and treated & 4.52 & .700 & 4.94 & .236 \\
\hline Overall Mean & 4.47 & & 4.94 & \\
\hline
\end{tabular}

Decision rule: If mean $(\overline{\mathrm{X}}) \leq 1.00=$ Very low level; $1.1-2.0=$ low level; 2.1-3.0=Average; 3.1-4.0=high level; 4.1-5.0=very high level.

At the pre-intervention stage, level of knowledge of both control $(\overline{\mathrm{x}}=4.13)$ and experimental $(\overline{\mathrm{x}}=4.26)$ groups were high. This implies that the respondents had a fore knowledge of the new methods of substance abuse among adolescents. This affirms the result of Parmar's study (2018) who analysed the knowledge and awareness regarding substance addiction in medical students of Valsad district of Gujarat, India. The study reveals that most of the students had knowledge about drug addiction and habituation, physiological and psychological dependence due to drugs and various methods for addiction of various drugs, which is quite similar to this study as teachers already had knowledge of adolescents abusing new forms of substances. However, post-intervention result shows an increase in the teachers' level of knowledge even among the control groups $(\overline{\mathrm{x}}=4.47)$ while the experimental groups showed $(\overline{\mathrm{x}}=4.94)$ on the new methods of substance abuse among students in secondary schools in Lagos State. The study of Mahmood, Othman, Al-Tawli \& Al-Hadithi (2018) shows that after the intervention, none of the students had poor knowledge and relatively half of the students had 
good knowledge level. This is similar to the finding of this study which shows that after the intervention, the teachers' level of knowledge of substance abuse among adolescents increased significantly showing that they know that adolescents abuse alternative drugs such as markers, tyres, rubbers, plastics amongst others.

4.3: Perception of teachers on substance abuse among students in selected secondary schools in Lagos pre and post intervention

Table 4.5: Pre-intervention perception of teachers on substance abuse among students

\begin{tabular}{|l|l|l|l|l|}
\hline & Control & \multicolumn{2}{l|}{ Experimental } \\
\hline Perception of Teachers on Substance abuse among students & Mean & SD & Mean & SD \\
\hline $\begin{array}{l}\text { Students involved in substance abuse are people suffering from unfortunate } \\
\text { life experiences }\end{array}$ & 3.07 & 1.035 & 3.57 & 1.037 \\
\hline Students involved in substance abuse will be criminals later in future & 3.07 & 1.269 & 3.46 & 1.067 \\
\hline Students involved in substance abuse should be sent to a rehabilitation centre & 4.19 & .921 & 4.40 & .847 \\
\hline $\begin{array}{l}\text { Prevention programmes that educate students regularly on substance abuse } \\
\text { should be introduced }\end{array}$ & 4.33 & .920 & 4.57 & .698 \\
\hline Students found guilty of substance abuse should be suspended or expelled & 3.26 & 1.059 & 3.54 & 1.067 \\
\hline $\begin{array}{l}\text { I can play a significant role in identifying a student involved in drug abuse and } \\
\text { can re-direct him or her }\end{array}$ & 4.00 & .961 & 3.94 & 1.027 \\
\hline Grand mean & $\mathbf{3 . 6 5}$ & $\mathbf{1 . 0 2 7}$ & $\mathbf{3 . 9 1}$ & $\mathbf{. 9 5 7}$ \\
\hline
\end{tabular}

Decision rule: If mean $(\overline{\mathbf{X}}) \leq \mathbf{1 . 0 0}=$ Very low level; $1.1-2.0=$ low level; 2.1-3.0=Average; 3.1-4.0=high level; 4.1-5.0=very high level.

Table 4.6: Post-intervention perception of teachers on substance abuse among students

\begin{tabular}{|l|l|l|l|l|}
\hline & \multicolumn{2}{l|}{$\begin{array}{l}\text { Control } \\
\text { group }\end{array}$} & \multicolumn{2}{l|}{$\begin{array}{l}\text { Experimental } \\
\text { group }\end{array}$} \\
\hline Practices of Teachers against Substance abuse among students & \multicolumn{1}{|l}{ Mean } & SD & \multicolumn{1}{|l|}{ Mean } & SD \\
\hline $\begin{array}{l}\text { Students involved in substance abuse are people suffering from } \\
\text { unfortunate life experiences }\end{array}$ & 3.52 & 1.051 & 4.63 & .843 \\
\hline Students involved in substance abuse will be criminals later in future & 3.44 & 1.188 & 4.74 & .780 \\
\hline $\begin{array}{l}\text { Students involved in substance abuse should be sent to a rehabilitation } \\
\text { center }\end{array}$ & 4.19 & .921 & 4.86 & .550 \\
\hline $\begin{array}{l}\text { Prevention programmes that educate students regularly on substance } \\
\text { abuse should be introduced }\end{array}$ & 4.48 & 1.087 & 4.97 & .169 \\
\hline $\begin{array}{l}\text { Students found guilty of substance abuse should be suspended or } \\
\text { expelled }\end{array}$ & 3.00 & 1.000 & 3.09 & 1.597 \\
\hline $\begin{array}{l}\text { I can play a significant role in identifying a student involved in drug } \\
\text { abuse and can re-direct him or her }\end{array}$ & 4.48 & .580 & 4.74 & .741 \\
\hline Overall mean & $\mathbf{3 . 8 5}$ & & $\mathbf{4 . 5 0}$ & \\
\hline
\end{tabular}

Decision rule: If mean $(\overline{\mathbf{X}}) \leq 1.00=$ Very low level; 1.1-2.0 = low level; 2.1-3.0=Average; 3.1-4.0=high level; 4.1-5.0=very high level.

At the pre-intervention stage, both control groups $(\bar{x}=3.65)$ and experimental groups $(\bar{x}=3.91)$, showed a high perception on the new methods of substance abuse among students. Moreira, Silveira \& Andreoli (2009) in their study found out that the attitude of public educators towards drug abuse among students was significantly emphatic and associated to their academic qualifications and the amount of time spent in that position. This means that teachers who have a high level of perception of substance abuse among students may do so due to their years of experience. The current study also revealed that teachers' level of perception at post-intervention stage is very high. For the control groups, a high perception $(\overline{\mathrm{x}}=3.85)$ of substance abuse among students was also noticed while those in the experimental groups equally have a very high perception $(\overline{\mathrm{x}}=4.50)$. The instance of the control groups still support Moreira, Silveira \& Andreoli (2009) which shows that teachers have a high level of perception towards substance abuse among students based on different experiences. Whereas, for the experimental groups, Jones, Modeste, Marshak \& Fox (2013) support that at post-intervention stage, their perception was high. In the study, though on HIV/AIDS, the experimental group were more likely to plan to delay sexual initiation because of being exposed to an HIV/AIDS educational intervention. In relation to this study, given that the post intervention perception of the experimental groups was high, this means that there was an improvement in their perception of the roles they are to play in curbing substance.

\subsection{Test of Hypotheses}

The Paired samples T-test was adopted for the test of the three hypothesis formulated. The result of all 
hypothesis are for the experimental groups and excludes that of the control groups as there was no significant difference in knowledge, awareness and perception in the pre-test and post-test carried out.

The first hypotheses aimed at determining difference in the level of awareness of teachers before and after communication intervention was accepted as it was found that during the pre-intervention stage, participants in the experimental groups were very much aware that adolescents have innovated new forms of substance abuse such as inhalants which comprise of lighters, markers, nail polish, rophynol, codeine, amongst others apart from the conventional drugs of abuse. However, after being exposed to the intervention, the experimental groups exhibited a slight increase in level of awareness on the new forms of substance abuse among adolescents and suggested that adolescents be enlightened on the issue as well. In view of their post-intervention awareness, the teachers also highlighted other forms of alternative drugs of abuse that has been observed: soak away, aka tomtom (mixture of lacasera drink and tom tom) and mixture of coke with codeine. This is depicted in the post intervention mean $=92.54286$ compared to the pre-intervention mean $=71.4857, \mathrm{p}<.05$.

The second hypotheses examined the difference in teachers' knowledge of substance abuse among students before and after communication intervention. The study revealed at the pre- intervention stage that teachers in the experimental groups have a high level of knowledge $(\mathrm{M}=51.14)$ on the use of alternative drugs of abuse by adolescents. However, after they were exposed to the intervention, their level of knowledge was significantly different from their pre-intervention knowledge with the post-intervention knowledge mean of $(M=59.4), p<.05$.

Lastly, the third hypotheses of the study was aimed at determining if there is a significant difference in teachers' perception of substance abuse among students before and after communication intervention. The study found that teachers in the experimental groups have a high level of perception of substance abuse among students with the mean of $(\mathrm{M}=23.48)$, at the pre-intervention perception stage. After exposure, though, their level of perception was still high, there was a significant difference in their post-intervention perception level with the mean of $(\mathrm{M}=27.02), \mathrm{p}<.05$.

\section{Conclusions}

Communication intervention strategies have proven to be effective in the awareness, knowledge and perception of teachers on substance abuse among adolescents. In terms of awareness, participants' response after the communication interventions on the new methods of substance abuse among adolescents revealed that the teachers had a high level of awareness on the issue, as they were able to highlight other forms of alternative drugs of abuse. In regard to knowledge, participants' response after the communication interventions on the alternative substance abuse among adolescents shows that the teachers experienced an increase in knowledge. Participants' response after the communication interventions revealed that there was a improvement in the way substance abuse among adolescents is perceived. Overall, the use of communication intervention, specifically the use of seminars, posters and fliers were effective in increasing the level of awareness, knowledge and perception of teachers significantly. The implication of this is that substance abuse among adolescents can be curtailed at the place where this study and previous studies have proven to be the common place of practice - the school. Further, the study affirms the underlining assumptions of the elaboration likelihood theory that persuasive communication can be effective when the messages are thought-provoking and targeted at the emotions of participants. This was achieved with the seminar which featured videos, graphic images and stories portraying real life cases of adolescents suffering from drug addiction as well as its physical and psychological effects. By promoting prevention rather than severe punishments such as suspension or expulsion, the speaker impressed the teachers' desire to be willing to work with students to prevent occurrence or repeat of abuse. Hence, the reason why a shift in attitude was noticed. Also, the credibility of the source as emphasized by the propounders of the source credibility theory aided the effectiveness of the message. The feedback generated during the seminar shows that the teachers believed the different communications/messages directed at them through the posters and fliers which were circulated as well as the facts shared in the course of the seminar presentation. Summarily, it is concluded that communication interventions have positive effects on teachers' awareness, knowledge and perception of substance abuse among adolescents. Specifically, participants level of awareness of the different alternate substance abuse were significantly improved post-intervention, knowledge of harmful effects of drugs which include mental illness, withdrawal and failure to meet up with assignments increased, and, level of perception of the role they can play in identifying a student involved in drug abuse and re-directing him or her was significantly improved.

\section{Recommendations}

The following recommendations are put forward:

Having recognized the positive effects of communication intervention strategies in the awareness, knowledge and perception of teachers on substance abuse among adolescents,

I. Secondary school management and teachers must ensure that these non-conventional substances such as 
tyres, rubbers, markers, lighters, etc are not found around the school. If they must be, they must be properly monitored or kept away from students.

II. School authority need to provide more education on the emerging trend of substance abuse. This could be infused into the extra-curricular activities such as drama, songs or short presentations to expose them to the dangers of these drugs.

III. The school should also establish a counselling unit with a highly qualified and trained guardian counsellor who can help students who have fallen victim to the practice of non-conventional substance abuse.

IV. At Parent-Teachers meetings, teachers should do well to educate parents on the emerging trend of substance abuse among adolescents so they can take certain precautions to prevent the student from falling victim of substance abuse.

V. The government should also establish counselling units in the communities as well as provide schools with devices that can be used to detect individuals who use or abuse drugs.

\section{Acknowledgements}

The authors acknowledge the support of the management and staff of Angus Memorial High School, Topgrade Secondary School, Shomolu High School and Thonix Immaculate High School in Yaba/Shomolu, Lagos State, Nigeria. Their willingness to participate in this intervention contributed in making the study worthwhile and productive.

\section{References}

Afolabi, M.O, Ayilara, A.E, Akinyemi, A.O \& Ola-Olorun, J.O (2012). Survey of Drug Use Among Young People in Ife, Nigeria. African Journal of Drug \& Alcohol Studies, 11(2), 88-94.

Akannam, T. (2008). North-West rank highest in Drug addiction. Nigerian Drug Statistics by Zone. Retrieved from: http://www.nairaland.com/203955/nigerian-drug-statistics-zone

Alcohol and Drug Foundation (2018). Codeine. Retrieved from: https://adf.org.au/drug-facts/codeine/

Alcohol and Drug Foundation (2018). Drug facts - Inhalants. Retrieved from: https://adf.org.au/drugfacts/inhalants/

American Academy of Paediatrics (2007). The role of schools in combating illicit substance abuse. AAP News and Journals Gateway. Retrieved from: http://pediatrics.aappublications.org/content/120/6/1379

Anyanwu, O.U, Ibekwe, R.C, Ojinnaka, N.C. (2016). Pattern of substance abuse among adolescent secondary school students in Abakaliki. Cogent Medicine,3, 1-7.

Arevian, M. B. \& Khasholian, T. K. (2014). Impact of a peer-led educational program on knowledge and attitudes about prevention of substance abuse among Lebanese/Armenian adolescents: A pilot study. Journal of Community Medicine \& Health Education, 4(5), 2-6.

Bayamma, N. (2015) A study to assess the effectiveness of structured teaching programme on cervical cancer among the women at Venkatachalam, Nellore. Manager Nursing Journal, 4(2), 19-20.

Botvin, G. J., Griffin, K. W., Diaz, T. \& Iffil-Williams, M. (2001). Preventing binge drinking during early adolescence: one- and two-year follow-up of a school-based preventive intervention. Psychology of Addictive Behaviors, 15(4), 360-365.

Bradley, E. G. (2009) The effects of a school-based motivational intervention on adolescent substance abuse. Open Access Dissertations. $34 . \quad$ Retrieved from: https://scholarworks.umass.edu/open_access_dissertations/34

Canada's National Arts Centre (2018). What is a Poster? Persuading Presence. Retrieved from: http://artsalive.ca/collections/posters/whatisaposter.php?lang=en

Carey, J. W. (Eds.) (2008). Communication as culture: Essays on media and society. Routledge, 2(1), 6-240.

DeJong, W. \& Winsten, J. A. (1990) The use of mass media in substance abuse prevention. Health Affairs, 9(2), $30-46$.

Duchin, S. \& Sherwood, G. (1990). Posters as an educational strategy. The Journal of Continuing Education in Nursing, 21, 205-208.

European Monitoring Centre for Drugs and Drug Addiction (2013) Perspectives on drugs: Mass media campaigns for the prevention of drug use in young people. Retrieved from: emcdda.europa.eu/topics/pods/mass-media-campaigns.pdf

Fareo, D.O (2012). Drug abuse among Nigerian adolescents' strategies for counseling. The Journal of International Social Research, 5(20), 342- 347.

Griffin, K. W., Botvin, G. J., Nichols, T. R. \& Doyle, M. M. (2003). Effectiveness of a universal drug abuse prevention approach for youth at high risk for substance use initiation. Preventive Medicine, 36(1), 1-7.

Griffin, K. W. \& Botvin, G. J. (2010). Evidence-based interventions for preventing substance use disorders in adolescents. Child Adolesc Psychiatr Clin N Am, 19(3), 505-526. 
Harrington, J., Noble, L. M. and Newman, S. (2004). Improving patient's communication with doctors: A systematic review of intervention studies. Patient Education and Counseling, 52(1), 7-16.

Hetcht, M. L \& Miller-Drug, M. (2017). 'Keepin it real': A case history of a drug prevention intervention. Oxford Research Encyclopedias. Retrieved http://communication.oxfordre.com/view/10.1093/acrefore/9780190228613.001.0001/acrefore9780190228613-e-370

Hovland, C., \& Weiss, W. (1951). The influence of source credibility on communication effectiveness. Public Opinion Quarterly, 15, 635- 650.

Hovland, C., Janis, I. \& Kelley, H. (1953). Communication and Persuasion. New Haven, GT: Yale University Press.

Ilic, D. \& Rowe, N. (2013). What is the evidence that poster presentations are effective in promoting knowledge transfer? A state of the art review. Health Information and Libraries Journal, 30, 4-12.

Isiguzo, B.C. \& Obiechina, G.O. (2016). Curbing the menace of drug use among secondary school students in Nigeria. European Journal of Research and Reflection in Educational Sciences, 4, 53-64.

Jones, V., Modeste, N., Marshak, H. H. \& Fox, C. (2013) The effect of HIV/AIDS education on adolescents in Trinidad and Tobago. ISRN Infectious Diseases, 1-8

Kalantarkousheh, S. M., Rasouli, M., Abolfathi, R. \& Nouri, N. (2014). Effectiveness of communication skills in decreasing addiction tendencies among male students from cities within Tehran province. Pelagia Research Library, 4(1), 64-70.

Keely, B. (2004). Planning and creating effective scientific posters. The Journal of Continuing Education in Nursing, 35(4), 182-5.

Kendra, C. (2018). Attitude and behaviour in psychology. Verywellmind. Retrieved from: https://www.verywellmind.com/attitudes-how-they-form-change-shape-behavior-2795897

Lofland, K. (2014). Evidence-based Practices for effective communication and social intervention. Indiana Resource Center for Autism. Retrieved from: https://www.iidc.indiana.edu/pages/evidence-based-practicesfor-effective-communication-and-social-intervention

Logan, A. (2014). Effective preventative interventions of substance use. St. Catherine University Repository, 5, 3-53.

Mahmood, N., Othman, S., Al-Tawli, N. \& Al-Hadithi, T. (2018). Impact of an education intervention on knowledge of high school students concerning substance use in Kurdistan region-Iraq: A quasiexperimental study. PLoS ONE 13(10), 1-9.

Mamman, H., Othman, T. A. \& Lian, L. H. (2014). Adolescents and drug abuse in Nigeria. Journal of Biology, Agriculture and Healthcare, 4, 5-9.

National Drug Law Enforcement Agency Act. Retrieved from: http://lawnigeria.com/LawsoftheFederation/NATIONAL-DRUG-LAW- ENFORCEMENT-AGENCYACT.html

National Institute on drug Abuse. (2014). Principles of Adolescent Substance use disorder Treatment: $A$ research based-guide. Retrieved from: https:/www.drugabuse.gov/publications/principles-adolescent-substance-usedisorder-treatment-research-based-guide/introductionNational Association of Social Workers. (2003). National Association of Social Workers Standards for the practice of social work with adolescents. Retrieved from: http://www.naswdc.org/practice/standards/NASWAdolescentsStandards.pdf

Next Generation Village (2018) Teen inhalant abuse treatment. Retrieved from: https://www.nextgenerationvillage.com/drugs/inhalants/

Ojo, L. (2018). Drug abuse by Nigerian youth: Curbing a resurgent menace. Leadership Newspaper. Retrieved from: https://leadership.ng/2018/05/03/drug-abuse-by-nigerian-youth-curbing-a-resurgent-menace/

Okorie, N. (2013) Mass media strategies for creating awareness of breast cancer. Public Knowledge Journal, 2(1), 1-18.

Okoye, N. N. (2001). The adolescents and hard drugs: A psychological concern in R.U.N., Okonkwo \& R.O. Okoye (eds).

Okpala, D. C. (2015) The menace of drug abuse in Nigeria- A case study of Mararaba town, Karu local government area of Nassarawa state. Unpublished doctoral thesis. Institute of Social work and Geriatric studies, Abuja, Nigeria.

Ortega, J. V. \& Barriuso, B.P. (2013). The TEACCH program for children and adults with autism: A metaanalysis of intervention studies. Clinical Psychology Review, 33(8), 940-953.

Oshikoya, K. A \& Alli, A. (2006). Perception of drug abuse amongst Nigerian undergraduates. World Journal of Medical Sciences, 1(2), 133-139.

Parmar, P. (2018). Knowledge and awareness regarding substance addiction among medical students of Valsad, Gujarat. Forensic Sci Add Res, 4(1), 1-3.

Paul, R. (2008). Interventions to improve communication. Child Adolesc Psychiatr Clin N Am,17(4), 835-x. 
Pennisi, L. A., Gunawan, Y., Major, A. L. \& Winder, A. (2018). How to create an effective brochure. UNL Extension Publications. Retrieved from: http://extensionpublications.unl.edu/assets/pdf/g2028.pdf

Peters, D. (2018, December 20). Media campaigns- posters and flyers (WD). Retrieved from: https://sswm.info/water-nutrient-cycle/water-distribution/softwares/awareness-raising/media-campaigns--posters-and-flyers- $\% 28 \mathrm{wd} \% 29$

Petty, R. E. \& Cacioppo, J. T (1986). The elaboration likelihood model of persuasion. Advances in Experimental Social Psychology, 19, 123-205.

P.M. News (2017). Drug abuse: Psychiatrists decry high rate among adolescents. Retrieved from: https://www.google.com/amp/s/www.pmnewsnigeria.com/2017/10/18/drug-abuse-psychiatrists-decry-highrate-among-adolescents/amp/

Punch (2016). From lecture rooms to mental hospitals: How drug is killing Nigerian undergraduates. Retrieved from: https://punchng.com/lecture-rooms-mental-hospitals-drug-killing-nigerian-undergraduates/

Punch. (2017). Wild, wild life of drug and booze among youths. Retrieved on November 4, from: https://punchng.com/wild-wild-life-of-drugs-and-booze-among-youths/

Randolph, W. \& Viswanath, K. (2004). Lessons learned from public health mass media campaigns: marketing health in a crowded media world. Annual Review of Public Health, 25, 419-437.

Rimal, R. N \& Lapinski, M. K. (2009). Why health communication is important in public health. Bulletin of the World Health Organization, 87(4), 247- 247a.

Rimer, B. K \& Kreuter, M. W (2006). Advancing tailored health communication: A persuasion and message effects perspective. Journal of Communication, 56, 184-201.

Ronoh, K. C. (2014). Effectiveness of drug and substance abuse prevention programs in selected public and private universities in Kenya. Unpublished Post Graduate Dissertation. Kenyatta University.

Sahu, K. K \& Sahu, S. (2012). Substance abuse causes and consequences. Bangabasi Academic Journal, 9, $52-$ 59.

Samanez, T. C. (1987). The poster as a communication medium. Cuad Comun Amidep, 1, 33-8. Retrieved from: https://www.ncbi.nlm.nih.gov/pubmed/12281468

Snell, M., Brady, N., McLean, L., Ogletree, B. T., Siegel, E., Sylvester, L., Mollica, B. M., Paul, D., Romski, M. A. and Sevcik, R. (2010). Twenty years of communication intervention research with individuals who have severe intellectual and developmental disabilities. American Journal on Intellectual and Developmental Disabilities, 115(5), 364-380.

Soola, E. O. (2009). Communication and educational approaches and strategies for effective environmental awareness. European Journal of Social Sciences, 9(1), 15-28.

Stigler, M., Neuel, E. \& Perry, C. (2011). School based programs to Prevent and reduce alcohol use among youth. Alcohol research health, 34(2), 157-162.

Umeogu, B. (2012). Source Credibility: A philosophical analysis. Open Journal of Philosophy, 2(2), 112-115.

United Nations Office of Drugs and Crime (2004, November 4). School-based education for drug abuse prevention. United Nations Publications. Retrieved https://www.unodc.org/pdf/youthnet/handbook school english.pdf

United Nations Office on Drugs and Crime. (2007). Drug Abuse and Drug Dependence Treatment Situation, in Nigeria. According to UNODC data for the year 2007. Retrieved from: http://www.unodc.org/docs/treatment/CoPro/Web_Nigeria.pdf

Vanguard, (2013). Drug abuse and Nigerian youths. Retrieved from:: https://www.vanguardngr.com/2016/06/drug-abuse-and-nigerian-youths/

Vishal, V. P. (2018). Advantages and disadvantages of a seminar. Retrieved from:https://www.streetdirectory.com/travel_guide/277/business_and_finance/advantages_and_disadvantag es_of_a_seminar.html

Wakefield, M.A., Loken, B. and Hornik, R.C. (2010). Use of Mass Media Campaigns to Change Health Behaviour. The Lancet, 376, 1261-1271.

Young, M. (2011). What are schools for? Educação, Sociedade \& Culturas, 1(32), 145-155. 